\title{
Use of Mitomycin C in Ocular Surgery; A Narrative Review
}

\author{
P. S. Mahar
}

Pak J Ophthalmol 2019, Vol. 35, No. 3

See end of article for authors affiliations

Correspondence to:

P.S. Mahar

FRCS, FRCOphth

Consultant Eye Surgeon

Aga Khan University Hospital

Professor \& Dean

Isra Postgraduate Institute of Ophthalmology

Karachi

Email: salim.mahar@aku.edu
Mitomycin $\mathrm{C}$ is an alkylating agent with an anti-proliferative activity. Because of its potent anti-fibroblastic effect, it is used in multiple ocular surgical procedures where inhibition of proliferation of fibroblasts and vascular ingrowths is required. It is dispensed in blue violet crystalline powder and it dissolves in water. MMC is stable for 2 weeks when refrigerated at $2-8$ degrees centigrade after the powder is reconstituted for topical use. Because of its anti-fibroblastic activity, MMC is used in various ocular surgical procedures. The optimal dose of MMC is not known but is usually used in concentration of $0.1 \mathrm{mg} / \mathrm{ml}(0.01 \%)$ to $0.5 \mathrm{mg} / \mathrm{ml}$ $(0.05 \%)$ in different clinical setups.

Key Words: Mitomycin C, Fibroblasts, Ocular Surgery.
$\mathrm{M}$ itomycin is an alkylating agent with an anti-proliferative effect. It inhibits DNA synthesis of cells exhibiting highest rate of mitosis.

Mitomycin is isolated from soil bacterium streptomyces caesopitosus. It has got 3 types mitomycin A, mitomycin B and mitomycin $C$ which are produced by Streptomyces caesopitosus under different conditions. Therefore, this medication is called as mitomycin C (MMC) to differentiate it from others. ${ }^{1}$ Mitomycin $\mathrm{C}$ inhibits proliferation of fibroblasts, suppresses vascular ingrowths and is much more potent than 5 - fluorouracil $(5 \mathrm{FU})^{2}$. It is dispensed in blue violet crystalline powder and it dissolves in water. MMC is stable for 2 weeks when refrigerated at $2-8$ degrees centigrade after the powder is reconstituted for topical use. Because of its anti-fibroblastic activity, MMC is used in various ocular surgical procedures. The optimal dose of MMC is not known but is usually used in concentration of $0.1 \mathrm{mg} / \mathrm{ml}(0.01 \%)$ to $0.5 \mathrm{mg} / \mathrm{ml}(0.05 \%)$ in different clinical setups.

\section{PTERYGIUM SURGERY}

Pterygium is a fibro-vascular growth which extends across the limbus onto the cornea. It is a common corneal disorder witnessed in countries with hot climate. ${ }^{3}$ Once grown over cornea, apart from the cosmetic blemish, it induces irregular astigmatism. If it's growth involves the visual axis, it can also severely curtail the vision.

Surgical removal of the pterygium is the preferred treatment but the rate ofrecurrent pterygium is very high at $30 \%-50 \%$ after simple excision is performed ${ }^{4,5}$. Kunitomo and Mori ${ }^{6}$ were the first workers suggesting the adjunct use of MMC in patients undergoing surgical excision. In 1988, Hayasaka et $\mathrm{al}^{7}$ published their work on the instillation of lower dose of MMC after surgery in the treatment of primary pterygium. They found recurrence rate of $7 \%$ in group of patients treated with $0.2 \mathrm{mg} / \mathrm{ml} \mathrm{MMC} \mathrm{drops} \mathrm{used} \mathrm{for} 1$ week duration. The recurrence rate was $11 \%$ with the use of $0.4 \mathrm{mg} \mathrm{MMC}$ drops and 32\% recurrence was noted in their cohort of patients undergoing simple surgical excision. Singh 
and co-workers ${ }^{8}$ reported similar favourable results of non-recurrence in their patients using $1 \mathrm{mg} / \mathrm{ml} \mathrm{MMC}$ drops postoperatively. Mahar and Nwokora ${ }^{9}$ in their published work concluded no recurrence of pterygium when MMC $0.4 \mathrm{mg} / \mathrm{ml}$ drops were used postoperatively for 2 weeks duration.

Lack of optimal dosage and variable duration of instillation of MMC has led to some serious complications. Rubenfeld ${ }^{10}$ described group of patients developing secondary glaucoma, corneal edema, corectopia, corneal perforation, Iritis and scleral calcification when MMC was used in higher concentration and for long duration of upto 4 weeks.

This treatment modality was followed by many clinicians to use MMC intra-operatively in a single dose after surgical excision. This has not only successfully reduced recurrence of Pterygium but showed minimal complications.

Cardillo and colleagues ${ }^{11}$ in a prospective study treated 227 patients with primary Pterygia. After surgical excision these patients were divided in 5 groups: group 1 received single intra-operative application of $0.2 \mathrm{mg} / \mathrm{ml} \mathrm{MMC} \mathrm{for} 3$ minutes; group 2 received a single intra-operative application of 0.4 $\mathrm{mg} / \mathrm{ml} \mathrm{MMC} \mathrm{for} 3$ minutes; group 3 received MMC eye drops $0.2 \mathrm{mg} / \mathrm{ml} 3$ times a day for 7 days; group 4 received $0.4 \mathrm{mg} / \mathrm{ml}$ MMC drops 3 times a day for 2 weeks and group 5 acted as control. At mean follow up of 28 months all groups receiving MMC in single application or drops showed around 5\% recurrence rate in comparison to control group with recurrence rate of $29.27 \%$. This study indicated that there was no difference in recurrence between intra-operative application of MMC or drops and also no statistically difference was found in groups receiving $0.2 \mathrm{mg} / \mathrm{ml}$ or $0.4 \mathrm{mg} / \mathrm{ml} \mathrm{MMC} \mathrm{for} 3$ minutes. Since thenmultiple studies have followed with intra-operative use of MMC in concentration of $0.2 \mathrm{mg} / \mathrm{ml}$ or $0.4 \mathrm{mg} / \mathrm{ml}$ with application time of $3-5$ minutes ${ }^{12,13,14}$.

Several workers have also used $0.1 \mathrm{ml}$ of MMC in concentration of $0.2 \mathrm{mg} / \mathrm{ml}$ injected under pterygium head and then removing pterygium with simple excision after 4 weeks. The success rate of this approach has been comparable to the topical application of MMC in reducing the recurrence rate of pterygium ${ }^{15,16}$.

\section{TRABECULECTOMY}

The aim of drainage surgery for glaucoma like trabeculectomy is to create an outflow channel for aqueous humor leading into subconjunctival space. The common cause of failure of this drainage area is to get occluded due to fibrosis at conjunctival - scleral interface and intrasclerally. The various risk factors for the fibrosis resulting in drainage failure are long term antiglaucoma medication, patients under 50 years of age and various uveitic, rubeotic and pseudophakic glaucomas. The scarring process occurs due to proliferation of fibroblasts at the site of surgical fistula ${ }^{17}$, resulting in uncontrolled intraocular pressure (IOP). Because of its anti fibroblastic activity, MMC has been used topically over sclerectomy area to maintain the drainage facility with controlled IOP.

The first use of MMC in trabeculectomy is attributed to chen ${ }^{18}$ who claimed higher success in his cohort of 59 eyes undergoing trabeculectomy in refractory glaucomas. This has been followed by numerous reports in the literature on the use of MMC in trabeculectomy in all types of glaucoma achieving higher success rate in maintaining the IOP19-23.

Traditionally MMC soaked sponges are placed at the time of surgery under conjunctiva before or after scleral flap dissection. The average concentration of MMC is $0.1 \mathrm{mg} / \mathrm{ml}-0.5 \mathrm{mg} / \mathrm{ml}$ with duration of application between $1-5$ minutes. Afterwards MMC is washed out with copious irrigation of balanced salt solution (BSS). Some clinicians have used the sponges placed under the scleral flap and claimed higher success of IOP control. ${ }^{24}$ One alternative approach for using MMC is to inject it subconjunctivally over the site of bleb at the start of the surgery ${ }^{25}$. Maquet and colleagues $^{26}$ described protocol for MMC use in glaucoma surgery. They divided 143 eyes of 124 patients in multiple groups receiving $M M C$ in different concentrations. First group received MMC $0.1 \mathrm{mg} / \mathrm{ml}$, second group had $0.2 \mathrm{mg} / \mathrm{ml}$ while third group of patients received $0.4 \mathrm{mg} / \mathrm{ml}$. No significant difference were found in final mean IOP values or in postoperative complications at the end of 12 month follow-up. Pakravan and co-workers ${ }^{27}$ in multicentre clinical trial randomized 80 patients in 2 groups: group 1 received Subtenon injection of $0.1 \mathrm{ml}$ of 0.1 $\mathrm{mg} / \mathrm{ml}$ MMC while group 2 received $0.2 \mathrm{mg} / \mathrm{ml}$ MMC soaked sponges. At the end of 1 year follow-up both groups showed success of $82.5 \%$ in controlling the IOP. They reported that, blebs tended to be more diffused, less vascularized and shallower in patients receiving MMC by subtenon injection.

The use of MMC is not without certain complications when used in higher concentration and for longer duration. Therefore, it is important to weigh 
the risks and benefits of MMC use in glaucoma surgery. The use of MMC can cause corneal epithelium toxicity resulting in superficial punctuate erosions and corneal abrasions. Conjunctival wound leaks are also frequently described in patients treated with MMC. The thin-walled blebs produced with MMC use are also at greater risk for developing blebitis and endophthalmitis. Hypotony and resulting maculopathy is also witnessed in patients receiving MMC during trabeculectomy ${ }^{28}$.

\section{REFRACTIVE SURGERY}

Photorefractive Keratectomy (PRK) is the original surface ablation technique involving removing the epithelium of the cornea mechanically with subsequent ablation of the bowman's layer and anterior stroma using the excimer laser. Although this technique is followed by pain and discomfort during the first 24 hours and slow visual recovery but it is the corneal haze formation which complicates the visual outcome. Corneal haze can develop frequently after treatment of high myopia ( $\geq 6.00$ Diopters) due to ablation depth. The pathogenesis of haze formation is due to keratocytes apoptosis caused by laser and is followed by proliferation and migration of surrounding keratocytes to repopulate the stroma. Some of these keratocytes differentiate into myofibroblasts which not only are basis for corneal haze but also cause scattering of light ${ }^{29}$.

Talamo was the first one using MMC in an animal model suggesting that it's use can prevent corneal haze formation ${ }^{30}$.

Mitomycin C is applied over the deepitheliazed stroma after laser ablation. It causes lower keratocytes and myofibroblasts density with reduced deposit of collagen and extracellular matrix resulting in decreased corneal haze ${ }^{31}$.

The optimal dose and duration of MMC is not known in PRK. But it is used in a concentration of $2 \mathrm{mg} / \mathrm{ml}(0.2 \%)-0.2 \mathrm{mg} / \mathrm{ml}(0.02 \%)$ with duration of application from 12 seconds to 2 minutes.

Majmudar first used MMC as a prophylactic agent in patients undergoing PRK. ${ }^{32}$ Leccisotti reported significant less haze in eyes treated with MMC 0.2 $\mathrm{mg} / \mathrm{ml}$ for 45 seconds. Patients refractive error ranged from - 6.50 to - 10 diopters $^{33}$. Similarly Wallu and Campos reported better outcome for PRK with MMC than LASIK with no haze observed in eyes treated with $\mathrm{MMC}^{34}$. Sigonos and colleagues advise 30 seconds application of MMC $0.2 \mathrm{mg} / \mathrm{ml}(0.02 \%)$ for primary PRK and in complicated cases involving penetrating keratoplasty (PKP), radial keratotmy (RK), and re-docases 1 minute or more application of MMC is suggested ${ }^{35}$. Medina and co-workers found no change in endoethelium cell count, epithelial thickness, keratocyte density and number of corneal nerve fibers with MMC use after 5 years postoperatively ${ }^{36}$.

\section{STRABISMUS SURGERY}

Postoperative scarring and formation of adhesions following strabismus surgery can compromise the final outcome. The intraoperative adjunctive use of MMC has been found with encouraging results in rabbit model with reduction in formation of adhesions and scarring ${ }^{37}$. Chen and colleagues ${ }^{38}$ found that use of MMC in dose of $0.2 \mathrm{mg} / \mathrm{ml}$ applied for 5 minutes duration was associated with better range of passive duction at all postoperative follow-ups in patients undergoing strabismus surgery. The use of MMC is also associated with delayed adjustments after strabismus surgery ${ }^{39}$.

\section{LACRIMAL SURGERY}

Dacryocystorhinostomy (DCR) is the preferred procedure in treating blockage of nasolacrimal duct with excessive lacrimation. The common cause of failure in DCR is closure of the common canaliculus and obstruction of the site of osteotomy ${ }^{40,41}$. This occurs due to proliferation of fibrous tissue, and formation of granulation tissue. The MMC soaked sponges $(0.2 \mathrm{mg} / \mathrm{ml})$ when placed at the site of osteotomy and anastomosed flaps can slow proliferation of fibrous tissue and development of scar. Liao and co-workers treated 44 eyes undergoingDCR surgery with application of MMC 0.2 $\mathrm{mg} / \mathrm{ml}$ applied to osteotomy site for 30 minutes. The non-patency rate in MMC group was $4.5 \%$ compared with $11.4 \%$ with conventional group. ${ }^{42}$ Rathore and colleagues placed a nasal pack soaked in $1 \mathrm{ml}$ of $0.5 \mathrm{mg} / \mathrm{ml}(0.05 \%) \mathrm{MMC}$ for 48 hours after endonasal DCR. Postoperatively, the nasal cavity with MMC pack had healthy nasal mucosa during the entire follow-up as compared to the control group with saline nasal pack which showed synechiae formation in $65.2 \%$ cases $^{43}$. Xue and co-workers conducted a meta-analysis of randomized controlled clinical trials related to adjunctive use of MMC in primary and revision external and endonasal DCR. They concluded 
that surgical success rate in primary and revision external DCR can be enhanced when MMC is applied at the site of osteotomy effectively but there was no significant advantage in primary endonasal DCR ${ }^{44}$. Nair et al in their review suggest that studies should be done on innovative drug delivery methods like intraoperative injection of MMC in depot form or using silicone stents coated with $\mathrm{MMC}^{45}$.

\section{CONCLUSION}

The use of mitomycin $C$ is established in various ocular surgical procedures. The optimal dose and duration of application of MMC is still not known. One has therefore to weigh the risks and benefits of its use in different clinical conditions.

\section{Financial Interest}

None.

\section{Conflict of Interest}

None.

\section{REFERENCES}

1. Wakaki S, Marcimo $\mathbf{H}$, Tomioka K. Isolation of new fractions of antitumor mitomycins. Antibiot Chemother. 1958; 8: 228-40.

2. Sutphin JE. Basic and clinical science course: External disease and cornea. San Francisco: American Academy of Ophthalmology, 2008; 8: 429-32.

3. Hill JC, Maske R. Pathogeneses of Pterygium. Eye, 1989; 3: 218-26.

4. De Keizer RJW. Pterygium excision with or without postoperative irradiation, a double-blind study. Doc Ophthalmol. 1982; 52: 309-15.

5. Zauberman H. Pterygium and its recurrence. Am J Ophthalmol. 1976; 63: 1780-6.

6. Kunitomo N, Mori S. Studies on pterygium. Report IV. A treatment of the pterygium by mitomycin $\mathrm{C}$ installation. Acta Soc Ophthalmol Jpn. 1963; 67: 1809-14.

7. Hayasaka S, Noda S, Yamamoto $Y$, Setogawa $T$. Postoperative instillation of low-dose mitomycin $\mathrm{C}$ in the treatment of primary pterygium. Am J Ophthalmol. 1988; 106: 715-8.

8. Singh G, Wilson MR, Foster S. Mitomycin eye drops as treatment for pterygium. Ophthalmology, 1988; 95: 81321.

9. Mahar PS, Nwokora GE. Role of Mitomycin C in pterygium surgery. Br J Ophthalmol. 1993; 77: 433-35.

10. Rubinfeld RS, Pfister RR, Stein RM, et al. Serious complications of topical Mitomycin-C after pterygium surgery. Ophthalmology, 1992; 99: 1647-54.

11. Cardillo JA, Alves MR, Ambrosio LE, Poterio MB, Jose
NK. Single intraoperative application versus postoperative Mitomycin C eye drops in pterygium surgery. Ophthalmology, 1995; 102: 1949-52.

12. Frucht-Pery J, Siganos CS, Ilsar M. Intraoperative application of topical Mitomycin C for Pterygium surgery. Ophthalmology, 1996; 103: 674-77.

13. Mastropasqua L, Carpineto P, Ciancaglini M, Gallenga PE. Long term results of intraoperative Mitomycin $C$ in the treatment of recurrent pterygium. Br J Ophthalmol. 1996; 80: 288-91.

14. Nuzzi R, Tridico F. How to minimize pterygium recurrence rates: clinical perspectives. Clin Ophthalmol. 2018 Nov. 19; 12: 2347-2362.

15. Donnenfeld ED, Perry HD, Fromer S, Doshi S, Solomon R, Biser S. Subconjunctival Mitomycin C as adjunctive therapy before pterygium excision. Ophthalmology, 2003; 110: 1012-26.

16. Khakshoor H, Razavi ME, Daneshvar R, Shakeri MT, Ghate MF, Ghooshkhanehi H. Preoperative subpterygeal injection Vs intraoperative Mitomycin C for pterygium removal; Comparision of results and complications. Am J Opthalmol. 2010; 150: 193-98.

17. Jampel HD, Mc Guigen LJB, Dunkelbergu GR et al. Cellular proliferation after experimental glaucoma filtration surgery. Arch Ophthalmol. 1988; 106: 89-94.

18. Chen C, Huang H, Bair J, Lee C. trabeculectomy with simultaneous topical application of mitomycin $\mathrm{C}$ in refractory glaucomas. J Ocular Pharmacol. 1990; 6: 17582.

19. Palmer SS. Mitomycin as adjunct chemotherapy with trabeculectomy. Ophthalmology, 1991; 98: 317-21.

20. Singh K, Mehta K, Shaikh NM et al. Trabeculectomy with intraoperative mitomycin C vs. 5 fluorouracil: Prospective randomized clinical trail. Ophthalmology, 2000; 107: 2305-9.

21. Bindish R, Condon GP, Schlosser JD, D' Antonio J, Lauer KB, Lehrer R. Efficacy and safety of mitomycin C in primary trabeculectomy. Ophthalmology, 2002; 109: 1336-42.

22. Panarelli JF, Banitt MR, Gedde SJ, Shi W, Schiffman JC, Feuer WJ. A Retrospective Comparison of Primary Baerveldt Implantation versus Trabeculectomy with Mitomycin C. Ophthalmology, 2016 Apr; 123 (4): 789-95.

23. Beckers HJ, Kinders KC, Webers CA. Five year results of trabeculectomy with mitomycin C. Graefes Arch Clin Exp Ophthalmol. 2003; 24 (12): 106-10.

24. Prata JA Jr, Minkler DS, Baerveldt G et al. Site of mitomycin C application during trabeculectomy. J Glaucoma. 1994; 3: 298-301.

25. Apostolov VI, Siarrov NP. Subconjunctival injection of low-dose Mitomycin C for treatment of failing human trabeculectomies. Int Ophthalmol. 1999; 201: 101-5.

26. Maquet JA, Dios E, Aragon J, Bailez C, Ussa F, Laguna N. Protocol for mitomycin C use in glaucoma surgery. Acta Ophthalmol Scand. 2005; 83: 196-200.

27. Pakravan M, Esfandiari H, Yazdani S et al. Mitomycin C augmented trabeculectomy: Sub-tenon injection versus soaked sponges: a randomized clinical trial. Br J 
Ophthalmol. 2017; 0: 1-6.

28. Fontana $\mathbf{H}$, Nouri- Mahdavi $\mathbf{K}$, Lumba J, Ralli $\mathbf{M}$, Caprioli J. Trabeculectomy with Mitomycin C: Outcomes and risk factors for failure in phakic openangle glaucoma. Ophthalmology, 2006; 113: 930-36.

29. Teus MA, Benito-Llopis L, Alio JL. Mitomycin C in corneal refractive surgery. Surv Ophthalmol. 2009; 54: 487-502.

30. Talamo JH, Gollamudi S, Green WR et al. Modulation of corneal wound healing after excimer laser Keratomileusis using topical mitomycin C and steroids. Arch Ophthalmol 1991; 109 (8): 1141-46.

31. Tomas-Juan J, Larranaga AM, Hanneken L. Corneal regeneration after photorefractive keratectomy: A review. J Opto. 2015; 8: 149-69.

32. Majmudar PA, Forstot SL, Nirankari VS, Dennis RF, Brenart R, Epstein RJ. Topical mitomycin-C for subepithelial fibrosis after refractive corneal surgery. Ophthalmology, 2000; 107: 89-94.

33. Leccisotti A. Mitomycin C in photorefractive keratectomy: effect on epithelization and predictability. Cornea, 2008; 27 (3): 288-91.

34. Wallau AD, Campos M. One-year outcomes of a bilateral randomized prospective clinical trial comparing PRK with mitomycin C and LASIK. Br J Ophthalmology, 2009; 93 (12): 1634-38.

35. Siganos DS, Katsanevaki VJ, Pallikaris IG. Correlation of subepithelial haze and refractive regression 1 month after photorefractive keratectomy for myopia. J Refract Surg. 1999; 15 (3): 338-42.

36. Midena E, Gambato C, Miotto S, Cortese M, Salvi R, Ghirlando A. Long-term effects on corneal keatocytes of mitomycin C during photorefractive keratectomy: a romdomized contralateral eye confocal microscopy study. J Refract Surg. 2007; 23 (9 Suppl.): S1011-4.

\section{Author's Affiliation}

Prof P.S. Mahar

Consultant Eye Surgeon, Aga Khan University Hospital

Professor \& Dean, Isra Postgraduate Institute of Ophthalmology, Karachi
37. Esme A, Yildirim C, Tatlipinar S, Duzcan E, Yaylali V, Ozden S. Effects of intraoperative sponge mitomycin C and 5-fluorouracil on scar formation following strabismus surgery in rabbits. Strabismus, 2004; 12 (3): 141-8.

38. Chen PL, Chen WY, Lu DW. Evaluation of mitomycin $\mathrm{C}$ in reducing postoperative adhesions in strabismus surgery. J Ocul Pharmacol Ther. 2005; 21 (5): 406-10.

39. Oh S, Chang BL, Lee J. Effects of mitomycin $C$ on delayed adjustment in experimental strabismus surgery. Korean J. Ophthalmol. 1995; 9: 51-58.

40. Allen K, Berlin AJ. Dacryocystorhinostomy failure: association with nasolacrimal silicone intubation. Ophthalmic Surg. 1989; 20: 486-9.

41. Rosen N, Sharir M, Moverman DC, Rosner M. Dacryocystorhinostomy with silicone tubes: evaluation of 253 cases. Ophthalmic Surg. 1989; 20: 115-9.

42. Liao SL, Kao SCS, Tseng JHS, Chen MS, Hou PK. Results of intraoperative mitomycin $\mathrm{C}$ application in dacryocystorhinostomy. Br J Ophthalmol. 2000; 84: 9036.

43. Rathore PK, KumariSodhi P, Pandey RM. Topical mitomycin $\mathrm{C}$ as a postoperative adjunct to endonasal dacryocystorhinostomy in patients with anatomical endonasal variants. Orbit. 2009; 28: 297-302.

44. Xue K, Mellington FE, Norris JH. Meta-analysis of the adjunctive use of mitomycin $\mathrm{C}$ in primary and revision, external and endonasal dacryocystorhinostomy. Orbit. 2014; 33 (4): 239-44.

45. Nair AG, Ali MJ. Mitomycin-C in dacryocystorhinostomy: From experimentation to implementation and the road ahead: A review. Indian J Ophthalmol. 2015 Apr; 63 (4): 335-9. Doi: 10.4103/03014738.158082. PMID: 26044474; PMCID: PMC4463559.

\section{Author's Contribution}

Prof. P.S Mahar

Study Design, Manuscript Writing. Data Collection. 